\title{
Fluorescence and infrared spectroscopies: a tool for the determination of the geographic origin of Emmental cheeses manufactured during summer
}

\author{
Romdhane KAROUI ${ }^{\mathrm{a}}$, Éric DUFOUR ${ }^{\mathrm{a} *}$, Laurent PILLONEL ${ }^{\mathrm{b}}$, Daniel PICQUE ${ }^{\mathrm{c}}$, \\ Thomas CATTENOZ ${ }^{\mathrm{c}}$, Jacques-Olivier BOSSET ${ }^{\mathrm{b}}$ \\ a UR Typicité des Produits Alimentaires, ENITA de Clermont-Ferrand, 63370 Lempdes, France \\ b Station Fédérale de Recherches Laitières de Liebefeld (FAM), 3003 Berne, Switzerland \\ c Laboratoire de Génie et Microbiologie des Procédés Alimentaires, INRA, \\ 78850 Thiverval Grignon, France
}

Received 29 October 2003 - Accepted 19 January 2004

Published online 7 June 2004

\begin{abstract}
Mid-infrared (MIR) and front-face fluorescence spectroscopies, coupled with chemometric techniques, were investigated for their potential for discriminating Emmental cheeses originating from various geographic origins. A total of 74 Emmental cheeses, produced during summer, from six countries, i.e., Denmark $(n=2)$, Finland $(n=4)$, Germany $(n=6)$, Austria $(n=8)$, France $(n=27)$ and Switzerland $(n=27)$ were analysed. Within the $1500-900 \mathrm{~cm}^{-1}$ spectral region, a good classification of samples was obtained for 83.7 and $77 \%$ of the calibration and validation data sets, respectively. Within the $3000-2800 \mathrm{~cm}^{-1}$ the classification was considerably worse (only 57.4 and $29.7 \%$ for the calibration and validation spectra, respectively). Protein tryptophan and vitamin A fluorescence spectra were recorded directly on cheese samples. Considering tryptophan fluorescence spectra, a good classification was observed for 76.4 and $63.5 \%$ of the calibration and the validation samples, respectively. A better classification was obtained from the vitamin A fluorescence spectra since 93.9 and $90.5 \%$ of the calibration and validation spectra, respectively, were correctly classified. Cheeses from Finland and Denmark were well separated using the $1500-900 \mathrm{~cm}^{-1}$ spectra and tryptophan or vitamin A fluorescence spectra. Considering cheeses from Germany, $100 \%$ of good classification was only obtained with vitamin A spectra. Cheeses from France and Switzerland were generally discriminated, but several samples were incorrectly classified. It was concluded that vitamin A fluorescence spectra may be considered a promising probe for the reliable evaluation of Emmental cheese origin.
\end{abstract}

Emmental cheese / geographic origin / authenticity / infrared / fluorescence / chemometry

Résumé - Les spectroscopies infrarouge et de fluorescence frontale : un outil pour la détermination de l'origine géographique des fromages Emmental de productions estivales. La spectroscopie moyen infrarouge et la spectroscopie de fluorescence frontale couplées aux techniques chimiométriques ont été utilisées pour discriminer des fromages Emmental provenant de diverses origines géographiques. Un total de 74 fromages Emmental, de productions estivales et provenant de six pays : Danemark $(n=2)$, Finlande $(n=4)$, Allemagne $(n=6)$, Autriche $(n=8)$, France

\footnotetext{
* Corresponding author: dufour@enitac.fr
} 
$(n=27)$ et Suisse $(n=27)$, ont été analysés. À partir des spectres moyen infrarouge et en considérant la région spectrale de $1500-900 \mathrm{~cm}^{-1}$, de bonnes classifications se montant à 83,7 et $77 \%$ ont été obtenues respectivement pour les échantillons principaux et de vérification. La classification obtenue à partir de la région spectrale $3000-2800 \mathrm{~cm}^{-1}$ a été considérablement plus mauvaise (seulement 57,4 et 29,7 \% des échantillons principaux et de calibration ont été bien classés). Les spectres de fluorescence des tryptophanes des protéines et de la vitamine A ont été enregistrés directement sur des échantillons de fromages. Considérant les spectres de fluorescence des tryptophanes des protéines, 76,4 et $63,5 \%$ des échantillons principaux et de vérification ont été bien classés. Une meilleure classification $(93,9$ et 90,5\%) a été obtenue à partir des spectres de fluorescence de la vitamine A pour les échantillons principaux et de vérification. Les fromages finlandais et danois ont été bien discriminés des autres fromages à partir, aussi bien, des spectres moyen infrarouge $(1500$ $900 \mathrm{~cm}^{-1}$ ), de fluorescence des tryptophanes des protéines ou de fluorescence de la vitamine A. Par ailleurs, $100 \%$ de bonnes classifications ont été observés pour les fromages allemands en utilisant les spectres de fluorescence de la vitamine A. À quelques exceptions près, les fromages français et suisses sont généralement bien discriminés les uns des autres. La vitamine A peut être considérée comme une sonde prometteuse pour l'évaluation de l'origine géographique des fromages Emmental.

Emmental / origine géographique / authenticité / infrarouge / fluorescence / chimiométrie

\section{INTRODUCTION}

Nowadays, objective and authentic food information is a major concern of many consumers, and it is gaining importance $[19,23]$. Labelling and compositional regulations, which may differ from country to country, have a fundamental place in determining which scientific tests are appropriate for a particular issue. Cheeses with origin identification are generally high-priced and bring in a higher benefit to the producers than ordinary cheeses. For consumers with an extensive choice of food commodities, authenticity is a guarantee of safety and eating quality.

Cheese characterisation is a very important task which has been classically undertaken by different physico-chemical methods to determine $\mathrm{pH}$-value, fat content, nitrogen fractions, volatile fatty acids, organic acids, etc. These methods are cumbersome, require a great deal of time and expense, and in some cases the results are not very accurate. Taking this into account, the development of new methods for cheese characterisation is of great importance.

Spectroscopic techniques are fast, relatively low-cost and provide a great deal of information with only one test. They are considered to be sensitive, non-destructive, rapid, environmentally friendly and noninvasive, which makes these methods suitable for on-line or at-line process control. In addition, these analytical tools require limited sample preparation. In the last decade, rapid spectroscopic measurements have advanced in quality control in many areas of food production. Spectroscopic methods for measurements of food quality include ultraviolet and visual absorption, fluorescence emission, near-infrared and mid-infrared absorption, Raman scattering, nuclear magnetic resonance and microwave absorption . These spectroscopic techniques are based on different regions of the electromagnetic spectrum and different physical principles resulting in different sensing capabilities. The methods, however, share the ability to provide rapid multivariate information on the sample being monitored, which in turn makes it possible to simultaneously determine several quality parameters [1].

Mid-infrared spectroscopy is a method used for milk and dairy product analysis. Indeed, each chemical substance (apart from some salts and very simple chemical compounds) has its own distinctive spectrum. Only substances occurring in a very low concentration (below $0.1 \%$ ) can be difficult to determine, as the noise of the 
method might be encountered in such a case. The main disadvantage of mid-infrared spectroscopy is the strong absorptions of water present in many food products. The $\mathrm{O}-\mathrm{H}$ bending band $\sim 1650 \mathrm{~cm}^{-1}$ effectively obscures potentially useful absorptions from proteins.

Fluorescence spectroscopy offers several inherent advantages for the characterisation of molecular interactions and reactions. It is 1000 times more sensitive than absorption spectroscopy. This spectroscopic technique is more specific and more sensitive than normal infrared technique, allowing measurements in the ppm range. In addition, fluorescent compounds are extremely sensitive to their environment. For example, tryptophan residues that are buried in the hydrophobic interior of a protein have different fluorescent properties than residues that are in a hydrophilic environment [16]. This environmental sensitivity enables the characterisation of conformational changes such as those attributable to the thermal, solvent or surface denaturation of proteins, as well as the interactions of proteins with other food components [3, $9,10,12,26]$.

Mid-infrared spectroscopy has been used to discriminate semi-hard cheeses varying by the ripening time [7, 17]. Considering identification or authentication of food products, several papers report that near-infrared spectroscopy may be used $[20,22]$. It has also been reported recently that front-face fluorescence spectroscopy is able to discriminate different marketed soft cheeses [13]. This technique has also been fruitfully applied for the determination of the geographic origin of Protected Denomination of Origin (PDO) Gruyère cheeses [8].

The overall objective of the present investigation was to study the reliability and accuracy of mid-infrared and fluorescence spectroscopies coupled with chemometric methods for identifying and determining the geographic origin of Emmental cheeses produced during summer and originating from 6 different countries.

\section{MATERIALS AND METHODS}

\subsection{Origin and selection of the cheese samples}

The main framework of this study and the sampling procedure have been described in detail by [24]. Cheese samples manufactured during summer were chosen with different ripening times according to the state of the market. Each region produces a cheese with typical characteristics, one of which is the ripening time, which can vary from six weeks to several months. The cheese samples considered in this study included 2 samples from Denmark, 4 samples from Finland, 6 samples from Germany, 8 samples from Austria, 27 samples from France and 27 samples from Switzerland. Total nitrogen $(\mathrm{TN})$, water-soluble nitrogen (WSN) and non-protein nitrogen (NPN) were determined on the samples according to [4]. The $\mathrm{pH}$ value was determined at room temperature using a penetrometric electrode (Mettler-Toledo, No. 104063123, AG Im Langacher, Greifensee, Switzerland).

\subsection{Mid-infrared spectroscopy}

Five grams of fresh samples were dispersed in $100 \mathrm{~mL}$ water with a Polytron PT2100 at $15000 \mathrm{rpm}$ for $60 \mathrm{~s}$. An aliquot of $60 \mu \mathrm{L}$ was applied to a polyethylene card (Thermo Electron, Courtabœuf, France) usable in the spectral range of $4000 \mathrm{~cm}^{-1}$ to $900 \mathrm{~cm}^{-1}$, except between $2918 \mathrm{~cm}^{-1}$ and $2849 \mathrm{~cm}^{-1}$, the region of absorption of the polyethylene card. The samples were dried overnight. The prepared cards were analysed in transmittance on a Nicolet Magna 750 IR spectrometer (Thermo Electron). Thirty-two interferograms with a resolution of $4 \mathrm{~cm}^{-1}$ were recorded and averaged. Each cheese was analysed in triplicate.

\subsection{Fluorescence spectroscopy}

Fluorescence spectra were recorded using a FluoroMax-2 spectrofluorimeter (SpexJobin Yvon, Longjumeau, France) mounted with a variable angle front-surface accessory. The incidence angle of the excitation 
radiation was set at $56^{\circ}$ to ensure that reflected light, scattered radiation, and depolarisation phenomena were minimised. The spectra of cheese samples $(2 \mathrm{~cm} \times 1 \mathrm{~cm} \times 0.5 \mathrm{~cm})$, mounted between two quartz slides, were recorded at $20^{\circ} \mathrm{C}$. The emission spectra of tryptophan residues $(305-400 \mathrm{~nm})$ were recorded with the excitation wavelength set at $290 \mathrm{~nm}$ and the excitation spectra of vitamin A (250-350 nm) were recorded with the emission wavelength set at $410 \mathrm{~nm}$. All spectra were corrected for instrumental distortions in excitation using a rhodamine cell as a reference channel. For each cheese, three spectra were recorded on different samples.

\subsection{Mathematical treatment of data}

MIR spectra, tryptophan fluorescence spectra and vitamin A fluorescence spectra were normalised by reducing the area under each spectrum to a value of 1 according to Bertrand and Scotter [2].

In a first step, Principal Component Analysis (PCA) was applied to the normalised spectra to investigate differences between the samples [11, 13, 14]. This statistical multivariate treatment is, normally, the first step in the data exploration that allows a visualisation of the main variability aspects of a data set, without the constraint of an initial hypothesis concerning the relationship within samples and between samples and responses (variables). The main goal of this procedure is to find relationships between the different parameters (objects and variables) and/or the detection of possible clusters within objects and/or variables.

In a second step, Factorial Discriminant Analysis (FDA) was performed on the first 20 Principal Components (PCs) resulting from the PCA applied to the MIR spectral data and fluorescence spectral data (tryptophan or vitamin A). The aim of this technique is to predict membership of an individual cheese sample following the definition of six qualitative groups: the groups were created according to the geographic origin of cheeses [25]. FDA was applied to the spectral collections divided into two data sets for calibration and validation. The two data sets were obtained by splitting the spectral collection, i.e., for each cheese, two spectra were put in the calibration group and the third spectrum was used to create the validation group. The aim of this approach was to test the robustness of the model. The method cannot be applied in a straightforward way to continuous spectra because of the high correlation occurring between the wavelengths. Advantages were found in the preliminary transformation of the data into their PCs.

From the selected variables, FDA assesses new synthetic variables which are linear combinations of the variables of origins called discriminant factors, and which are not correlated and allow the best separation of the qualitative groups. For that, it is possible to take the axes, which separate as well as possible the centres of gravity of the six groups after calculation of the discriminant factors. The individual cheese samples can be reallocated within the various groups. For each individual cheese sample, its distance from the various centres of gravity of each group is calculated. The individual cheese sample is assigned to the group with the nearest gravity centre. Comparison of the assigned group to the real group is an indicator of the quality of the discrimination. Similarity maps can be drawn, in analogy to those drawn for PCA.

Finally, the first 20 PCs of the PCA performed on each data set (i.e., $3000-2800 \mathrm{~cm}^{-1}$, $1700-1500 \mathrm{~cm}^{-1}$ and $1500-900 \mathrm{~cm}^{-1}$, tryptophan and vitamin A fluorescence spectra) were pooled into one matrix and this new table was analysed by FDA. The concatenation process for the calibration and the validation spectra consists of putting one beside the other in the same matrix, the PCs data sets of MIR and fluorescence spectra (tryptophan and vitamin A), in order to take into account the whole spectroscopic information collected. The aim of this approach was to improve the discrimination of Emmental cheeses using a number of different infrared and fluorescence spectra [5]. 
PCA and FDA were carried out using StatBoxPro (Grimmer Logiciels, Paris, France).

\section{RESULTS AND DISCUSSION}

\subsection{Mid-infrared spectroscopy}

Because each chemical compound in the sample contributes to the absorbance spectrum, the mid-infrared spectrum of a cheese contains more information for compounds whose concentrations are higher than $0.1 \%$. The absorption bands observed in the midinfrared (4000-900 $\mathrm{cm}^{-1}$ ) are mainly associated with fundamental valence vibrations of functional groups of the molecules. Most of the spectral information used for the discriminant analysis is located: (1) in the $3000-2800 \mathrm{~cm}^{-1}$ range corresponding to $\mathrm{C}-\mathrm{H}$ stretching; (2) in the region located between $1700-1500 \mathrm{~cm}^{-1}$ corresponding to the amide I and II; and (3) in the 1500 $900 \mathrm{~cm}^{-1}$ region called the fingerprint region [21].

As the spectra of the three investigated regions exhibited slight differences between cheeses (data not shown), PCA was applied, separately, to the three spectral regions $\left(3000-2800 \mathrm{~cm}^{-1}, 1700-1500 \mathrm{~cm}^{-1}\right.$ and $\left.1500-900 \mathrm{~cm}^{-1}\right)$. From these spectral regions, the similarity maps defined by principal component 1 (PC1) and principal component 2 (PC2) did not show any discrimination between the six groups of cheeses (data not shown).

In a second step, the ability of infrared data to differentiate between the six groups of cheeses was investigated by applying FDA to the first 20 PCs of the PCA performed on the three data tables. Six groups were created for the investigated cheeses (Denmark, Finland, Germany, Austria, France and Switzerland).

Considering the $3000-2800 \mathrm{~cm}^{-1}$ spectral region, the map defined by discriminant factors 1 and 2 took into account $67.5 \%$ of the total variance (data not shown). Cheeses from Denmark were clearly discriminated from the others according to discriminant factor 1 which accounted for $41 \%$ of the total variance. Cheeses from Finland, Germany, France and Switzerland overlapped and were somewhat confused on the map.

The data did not allow a good classification of all the samples. Only $57.4 \%$ (data not shown) and $29.7 \%$ (Tab. I) of the calibration and validation spectra were observed, respectively. This table illustrated that cheeses from Denmark were $100 \%$ correctly classified, while many more misclassifications were observed for the others. For the cheeses from France, as well as cheeses from Switzerland, only $22.2 \%$ of correct classifications were obtained.

Concerning the $1700-1500 \mathrm{~cm}^{-1}$ spectral region, the map defined by the discriminant factors 1 and 3 is shown in Figure 1. This map shows that cheeses from Denmark and Austria were well discriminated, while cheeses from France, Switzerland and Finland presented coordinates close to the origin.

For this data set, correct classification amounting to $84.5 \%$ (data not shown) and $48.6 \%$ (Tab. I) was observed for the calibration and validation spectra, respectively. In fact, none are $100 \%$ correctly classified (Tab. I). Table I shows that a better classification of France and Switzerland cheeses were observed compared with the 3000 $2800 \mathrm{~cm}^{-1}$ spectral region, whereas a worse classification was observed for cheeses from Austria. Indeed, $63 \%$ and $33.3 \%$ of correct classifications were observed for cheeses from Switzerland and Germany, respectively.

Regarding the mid-infrared spectral regions, the best results were obtained considering the $1500-900 \mathrm{~cm}^{-1}$ spectral region. The map defined by the discriminant factors 1 and 5 is shown in Figure 2. Considering discriminant factor 1 , which accounts for $41.6 \%$ of the total variation, cheeses from Austria presented positive score values, while cheeses from Finland had negative score values. In addition, cheeses from Denmark had positive score values according to 
Table I. Classification table for the spectra for the validation group from the MIR and fluorescence spectra.

\begin{tabular}{|c|c|c|c|c|c|c|c|}
\hline Real $^{\text {Predicted }}$ & Denmark & Finland & Austria & Germany & France & Switzerland & $\begin{array}{l}\% \text { well } \\
\text { classified }\end{array}$ \\
\hline \multicolumn{8}{|c|}{ MIR: $3000-2800 \mathrm{~cm}^{-1}$ spectral region } \\
\hline Denmark & 2 & - & - & - & - & - & 100 \\
\hline Finland & 1 & 1 & - & 1 & 1 & - & 25 \\
\hline Austria & 2 & - & 3 & 3 & - & - & 37.5 \\
\hline Germany & - & 1 & - & 4 & - & 1 & 66.7 \\
\hline France & 1 & 6 & 3 & 7 & 6 & 4 & 22.2 \\
\hline Switzerland & 2 & 4 & 1 & 5 & 9 & 6 & 22.2 \\
\hline \multicolumn{8}{|c|}{ MIR: $1700-1500 \mathrm{~cm}^{-1}$ spectral region } \\
\hline Denmark & 1 & 1 & - & - & - & - & 50 \\
\hline Finland & - & 2 & 1 & - & - & 1 & 50 \\
\hline Austria & - & 1 & 1 & 3 & 2 & 1 & 12.5 \\
\hline Germany & - & - & 1 & 2 & 2 & 1 & 33.3 \\
\hline France & 2 & 5 & 3 & 3 & 13 & 1 & 55.6 \\
\hline Switzerland & 1 & 3 & 2 & 1 & 3 & 17 & 63.0 \\
\hline \multicolumn{8}{|c|}{ MIR: $1500-900 \mathrm{~cm}^{-1}$ spectral region } \\
\hline Denmark & 2 & - & - & - & - & - & 100 \\
\hline Finland & - & 4 & - & - & - & - & 100 \\
\hline Austria & - & - & 7 & - & 1 & - & 87.5 \\
\hline Germany & - & - & - & 3 & - & 3 & 50 \\
\hline France & - & - & 1 & - & 22 & 4 & 81.5 \\
\hline Switzerland & 1 & - & 1 & 1 & 4 & 19 & 70.4 \\
\hline \multicolumn{8}{|c|}{ Tryptophan fluorescence spectra } \\
\hline Denmark & 2 & - & - & - & - & - & 100 \\
\hline Finland & & 4 & - & - & - & - & 100 \\
\hline Austria & 1 & 1 & 6 & - & - & - & 75 \\
\hline Germany & - & 2 & - & 3 & - & 1 & 50 \\
\hline France & 5 & 4 & - & 1 & 14 & 3 & 51.9 \\
\hline Switzerland & - & 3 & 3 & - & 3 & 18 & 66.7 \\
\hline \multicolumn{8}{|c|}{ Vitamin A fluorescence spectra } \\
\hline Denmark & 2 & - & - & - & - & - & 100 \\
\hline Finland & - & 4 & - & - & - & - & 100 \\
\hline Austria & - & - & 7 & - & 1 & - & 87.5 \\
\hline Germany & - & - & - & 6 & - & - & 100 \\
\hline France & - & - & - & - & 24 & 3 & 88.9 \\
\hline Switzerland & - & - & 1 & 1 & 1 & 24 & 88.9 \\
\hline
\end{tabular}

${ }^{\mathrm{a}}$ The number of cheeses predicted from the model. ${ }^{\mathrm{b}}$ The number of real cheeses. 


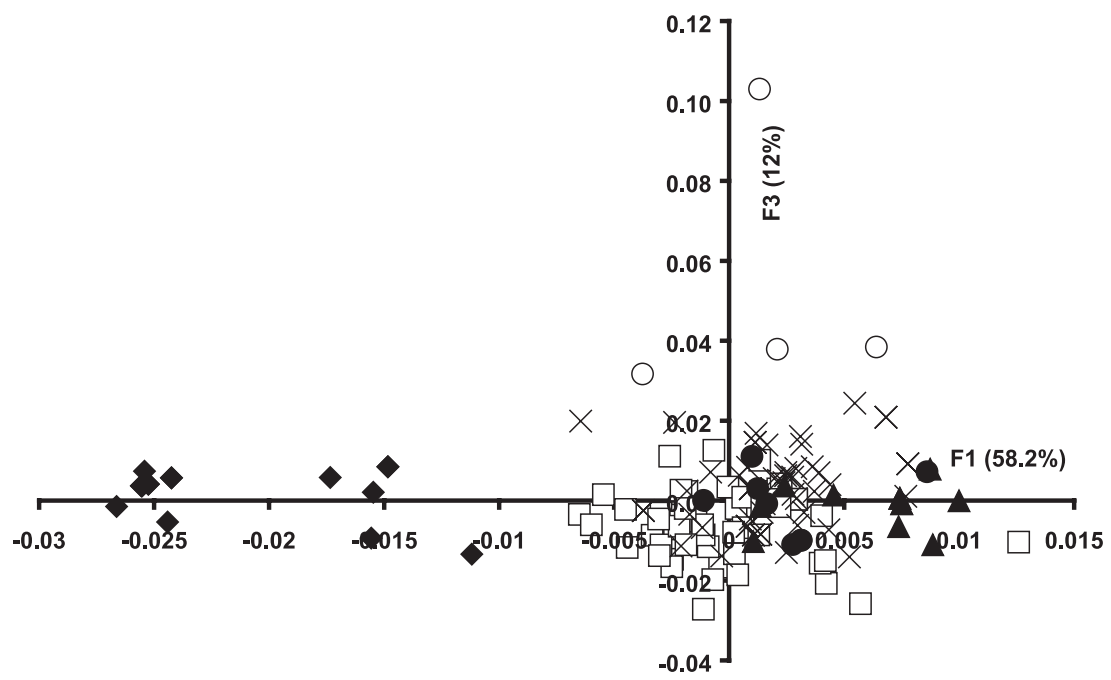

Figure 1. Discriminant analysis similarity maps determined by discriminant factors 1 and 3 for $1700-1500 \mathrm{~cm}^{-1}$ spectral region of the investigated cheeses: Austria $(\diamond)$, Switzerland $(\square)$, Germany $(\mathbf{\Delta})$, France $(\times)$, Finland $(\boldsymbol{O})$ and Denmark $(O)$.

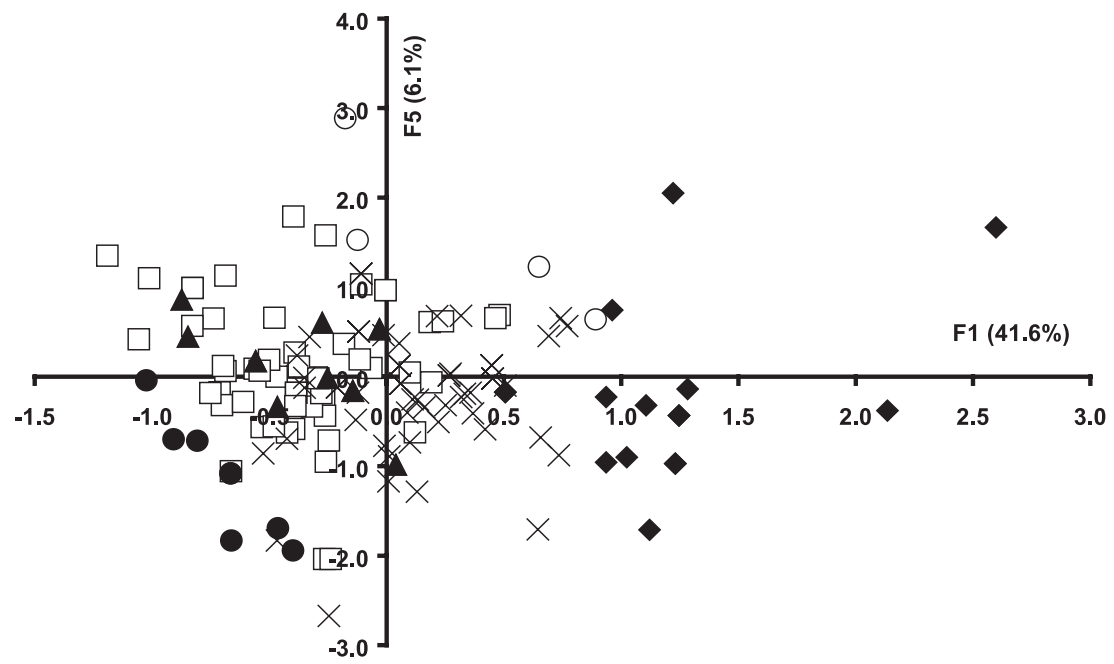

Figure 2. Discriminant analysis similarity maps determined by discriminant factors 1 and 5 for 1500-900 $\mathrm{cm}^{-1}$ spectral region of the investigated cheeses: Austria $(\diamond)$, Switzerland $(\square)$, Germany ( $\mathbf{\Delta})$, France $(\times)$, Finland $(\boldsymbol{O})$ and Denmark $(\mathrm{O})$.

discriminant factor 5, while cheeses from France, Switzerland and Germany were somewhat overlapping on the map.
A correct classification was observed for $83.7 \%$ (data not shown) and $77 \%$ (Tab. I) of the calibration and validation samples, 


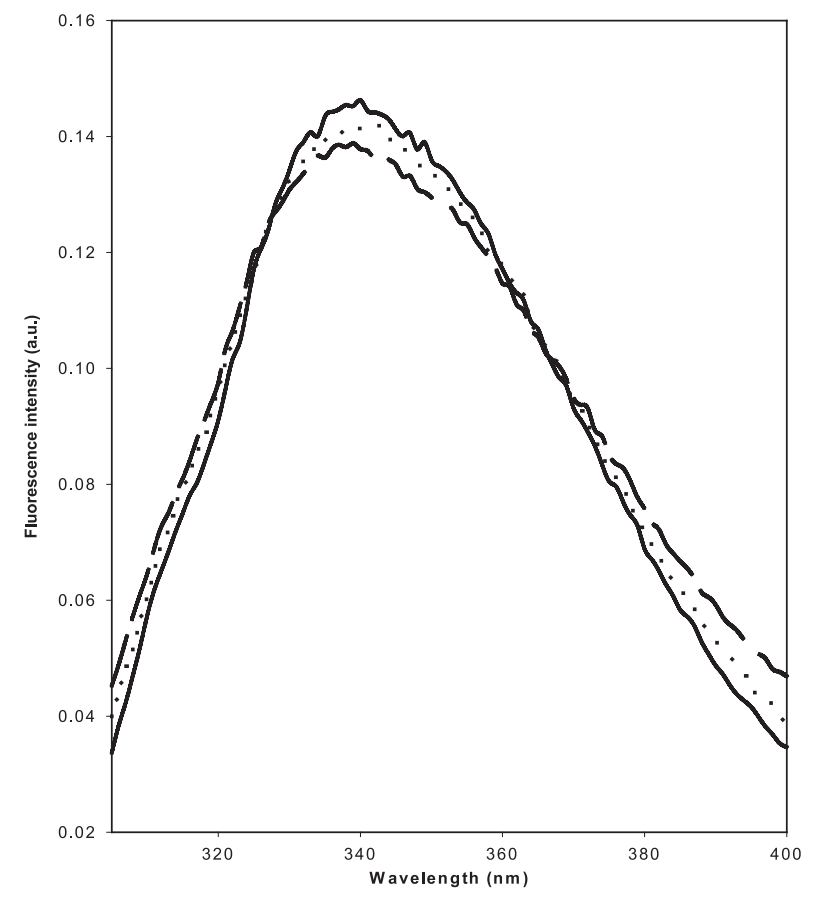

Figure 3. Normalised tryptophan fluorescence spectra recorded on investigated Emmental cheeses: Germany $(\rightarrow$, France (....) and Denmark $(-\longrightarrow$ ) respectively. $100 \%$ of correct classification was observed for cheeses from Finland and Denmark. Considering cheeses from France, a better classification was observed since only five samples were misclassified: one sample was in the Austria group and four samples were found in the Switzerland group. Considering Austrian cheeses, only one cheese was misclassified. The worst classification was obtained with cheeses from Germany since only $50 \%$ of good classification was obtained. Indeed, three samples were classified as belonging to the Switzerland group.

Concerning mid-infrared, the results of the discriminant analysis were better with the $1500-900 \mathrm{~cm}^{-1}$ spectral region than the two others. This region might be useful for the evaluation of the geographic origin of Emmental cheeses.

\subsection{Fluorescence spectra of the investigated cheeses}

It has been reported that fluorescence spectroscopy is a very sensitive technique, able to measure trace substances containing one or more fluorescent chemical groups. Important fluorophores of relevance to food products include vitamin A located in fat globules and proteins containing fluorescent amino acids such as tryptophan, tyrosine and phenylalanine residues [16].

Figure 3 presents the spectra of three investigated cheeses recorded following excitation at $290 \mathrm{~nm}$. The maximum emission of tryptophan residues was observed at about $339 \mathrm{~nm}$ and shifted slightly as a function of the origin of the cheese. Considering vitamin A, the excitation spectra of the cheeses (emission at $410 \mathrm{~nm}$ ) showed a maximum at $320 \mathrm{~nm}$, another peak at $305 \mathrm{~nm}$ and a shoulder at $295 \mathrm{~nm}$ (Fig. 4). In addition, as the shapes of the spectra showed great differences with the geographic origin of the cheeses, they may be considered as fingerprints that should allow their identification. Indeed, cheeses from Germany had the highest intensity at 320 and $305 \mathrm{~nm}$, while those from Denmark had the lowest. Recently, it has been reported that the shape 


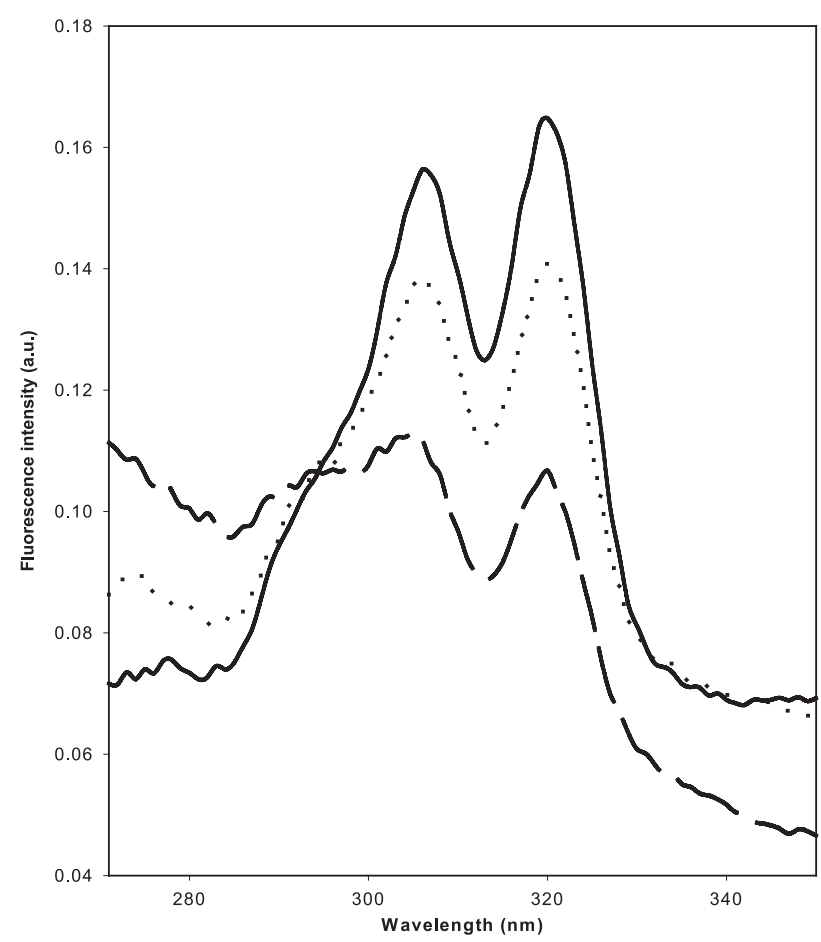

Figure 4. Normalised vitamin A fluorescence spectra recorded on investigated Emmental cheeses: Germany $(\rightarrow$, France (...) and Denmark $(-\longrightarrow)$. of the vitamin A excitation spectrum is correlated with the physical state of the triglycerides in the fat globules $[6,7,15]$ : the ratio of fluorescence intensity $F . I .322 \mathrm{~nm}$ ' F.I. $295 \mathrm{~nm}$ decreased during the melting of the triglycerides which could be explained by the decrease in the viscosity of triglycerides. Considering the data reported in this paper, the F.I. $322 \mathrm{~nm} / F . I_{.295} \mathrm{~nm}$ ratios were different from one cheese to another: cheeses from Germany and Finland had the highest ratios i.e., 1.45 and 1.51 , respectively, while those from Austria and Denmark had the lowest ones i.e., 1.09 and 0.94 , respectively. It has been shown that the fluorescent properties of fluorophores are very sensitive to the changes in the solvent viscosity [5, 7]. The changes in the F.I.322 nm F.I. $295 \mathrm{~nm}$ ratio were also observed during the ripening of semi-hard cheeses, indicating the crystallisation of triglycerides between $1 \mathrm{~d}$ and $81 \mathrm{~d}$ of ripening [7]. Finally, it has been suggested that the changes in the shape of vitamin A spectra may also result from fluorescence transfer between tryptophan residues of proteins and vitamin A located in the fat globule membrane [11].

\subsection{Discrimination of Emmental cheeses from their tryptophan fluorescence spectra}

In order to compare the set of tryptophan fluorescence spectra and to emphasise the similarities and differences underlined above, PCA was carried out on the 222 spectra recorded on the 74 cheeses. The scores scatter plots of PC1 versus PC2 of the 222 tryptophan fluorescence spectra represent $91.3 \%$ of the total variability with a predominance of $\mathrm{PC} 1$ accounting for $53.7 \%$ of the variance (data not shown). Examining a two-dimensional scores plot in the space defined by the PC1 and the PC2, a slight discrimination was observed between the investigated cheeses. 

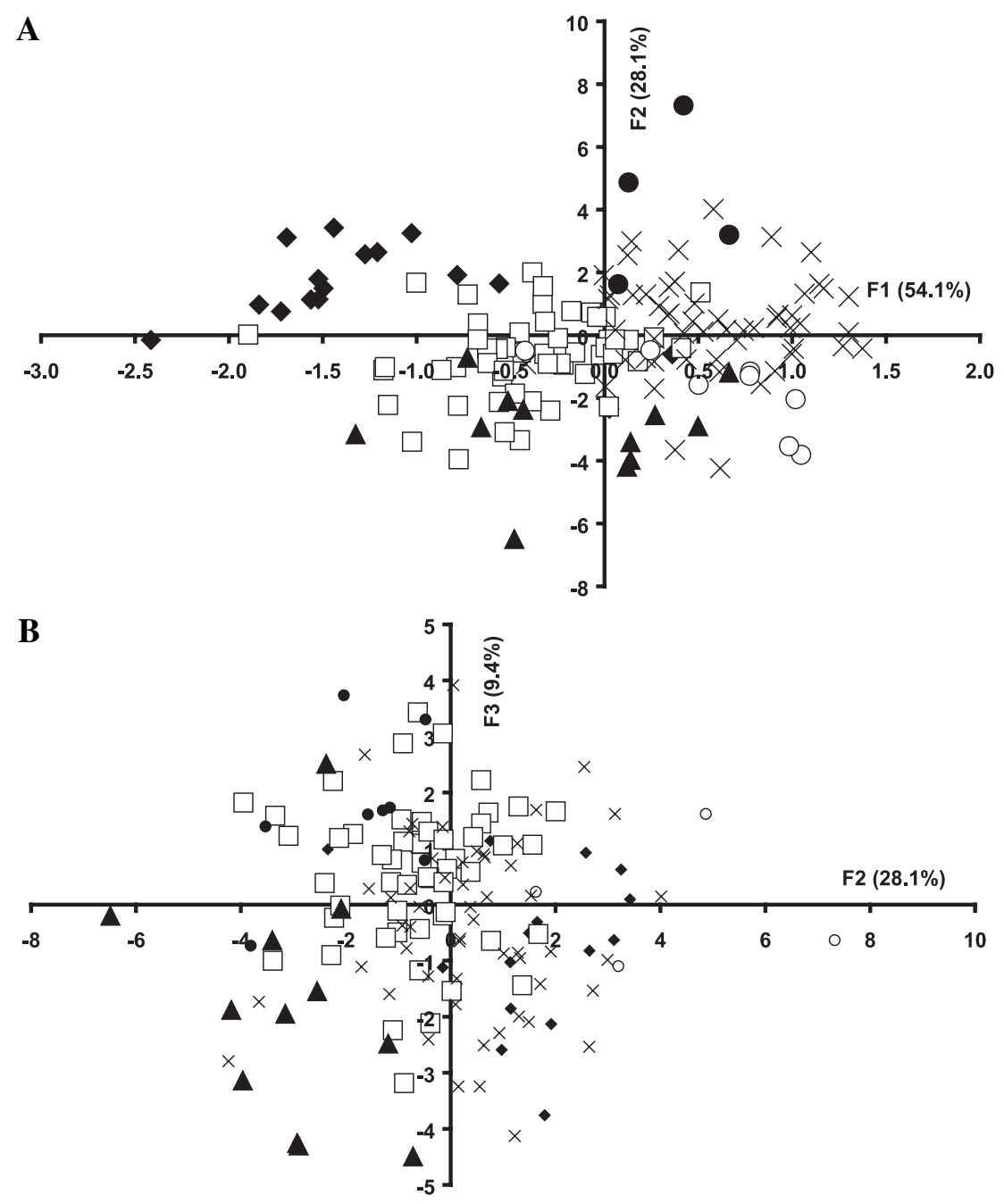

Figure 5. Discriminant analysis similarity maps determined: (A) by discriminant factors 1 and 2 for tryptophan spectra and (B) by discriminant factors 2 and 3. FDA performed on tryptophan spectra of the investigated cheeses: Austria $(\diamond)$, Switzerland $(\square)$, Germany $(\boldsymbol{\Delta})$, France $(\times)$, Finland $(\bullet)$ and Denmark $(O)$.

The discriminant ability of the data was then investigated by applying FDA to the first 20 PCs. The map defined by discriminant factors 1 and 2 is shown in Figure 5A. Although cheeses from Switzerland and France were partly overlapping on the map, a pretty good separation of the cheeses from Austria, Finland and Denmark was observed according to discriminant factor 1 , which accounted for $54.1 \%$ of the total variance. In fact, it appeared that: (1) cheeses from Austria exhibited negative scores according to discriminant factor 1 and positive score values according to discriminant factor 2; (2) cheeses from Finland showed positive score values according to discriminant 
Table II. Gross physico-chemical composition of the investigated Emmental cheeses.

\begin{tabular}{lcccccccccccc}
\hline & $\begin{array}{c}\text { Denmark } \\
(n=2)\end{array}$ & $\begin{array}{c}\text { Finland } \\
(n=4)\end{array}$ & $\begin{array}{c}\text { Germany } \\
(n=6)\end{array}$ & $\begin{array}{c}\text { Austria } \\
(n=8)\end{array}$ & $\begin{array}{c}\text { France } \\
(n=27)\end{array}$ & $\begin{array}{c}\text { Switzerland } \\
(n=27)\end{array}$ \\
\cline { 2 - 11 } & Mean & SD & Mean & SD & Mean & SD & Mean & SD & Mean & SD & Mean & SD \\
\hline $\mathrm{pH}$ & 5.70 & nd & 5.75 & 0.11 & 5.70 & 0.05 & 5.73 & 0.07 & 5.68 & 0.09 & 5.61 & 0.04 \\
$\mathrm{TN}\left(\mathrm{g} \cdot \mathrm{kg}^{-1}\right)$ & 44.56 & nd & 45.17 & 2.21 & 44.36 & 0.77 & 45.13 & 1.16 & 45.40 & 1.19 & 44.40 & 1.80 \\
WSN $\left(\mathrm{g}^{\left.-\mathrm{kg}^{-1}\right)}\right.$ & 12.48 & nd & 10.44 & 1.52 & 9.90 & 0.92 & 9.27 & 1.02 & 9.48 & 2.23 & 10.29 & 0.95 \\
NPN $\left(\mathrm{g} \cdot \mathrm{kg}^{-1}\right)$ & 10.19 & nd & 6.84 & 1.58 & 7.86 & 1.53 & 7.20 & 0.88 & 7.18 & 2.18 & 7.37 & 1.20 \\
WSN/TN $\left(\mathrm{g} \cdot \mathrm{kg}^{-1}\right)$ & 28.02 & nd & 23.11 & 0.69 & 22.32 & 1.19 & 20.54 & 0.88 & 20.89 & 1.88 & 23.17 & 0.54 \\
\hline
\end{tabular}

TN: total nitrogen; WSN: water soluble nitrogen; NPN: non protein nitrogen; SD: standard deviation; nd: not determined; $n$ : number of cheese samples.

factors 1 and 2; and (3) cheeses from Denmark were characterised by positive values according to discriminant factor 1 and negative score values according to discriminant factor 2 (Fig. 5A). The cluster formed by cheeses from France, Finland, Switzerland and Denmark included the Emmental with the highest water-soluble nitrogen $\left(9.48 \mathrm{~g} \cdot \mathrm{kg}^{-1} \pm\right.$ $2.23,10.44 \mathrm{~g} \cdot \mathrm{kg}^{-1} \pm 1.52,10.29 \mathrm{~g} \cdot \mathrm{kg}^{-1} \pm$ 0.95 and $12.48 \mathrm{~g} \cdot \mathrm{kg}^{-1}$, respectively) whereas cheeses from Austria and Germany had the lowest values $\left(9.27 \mathrm{~g} \cdot \mathrm{kg}^{-1} \pm 1.02\right.$ and $9.90 \mathrm{~g} \cdot \mathrm{kg}^{-1} \pm 0.92$, respectively) (Tab. II). From the similarity map 1-2 (Fig. 5A), it appears that cheeses from Switzerland and Germany were poorly discriminated. However, the map defined by discriminant factors 2 and 3 shows a good discrimination of these two groups of cheeses (Fig. 5B). These results suggest that a tryptophan fluorescence probe may be a potential technique for recognising the geographical origin of Emmental cheeses.

For the tryptophan data set, a correct classification was observed for $76.4 \%$ (data not shown) and $63.5 \%$ (Tab. I) of the calibration and validation samples, respectively. Table I gives the classification of the validation spectra in the six groups. It illustrates that a correct classification of cheeses from Finland and Denmark was observed, while some misclassification occurred for cheeses from France, Switzerland, Germany and Austria. For the cheeses from Switzerland, only $66.7 \%$ of correct classification was obtained. Indeed, nine samples were not assigned to the Switzerland group.

\subsection{Discrimination of Emmental cheeses from their vitamin A fluorescence spectra}

A number of 222 spectra was collected for the 74 cheeses originating from different countries and PCA was applied to this data set. The map defined by PCs 1 and 4 $(81.2 \%$ and $1.1 \%$ of the total variance, respectively) showed some discrimination of the cheeses (data not shown).

In a second step, FDA was applied to the first 20 PCs. The map defined by discriminant factors 1 and 2 is shown in Figure 6A. The two discriminant factors took into account $73.1 \%$ of the total variance with discriminant factor 1 accounting for $49.2 \%$. It showed that cheeses from Austria, France, Finland and Denmark were well separated, while cheeses from Germany and Switzerland were somewhat overlapping on the map. However, a good discrimination of cheeses from Germany and Switzerland was observed according to the map defined by discriminant factors 2 and 4 (Fig. 6B). 

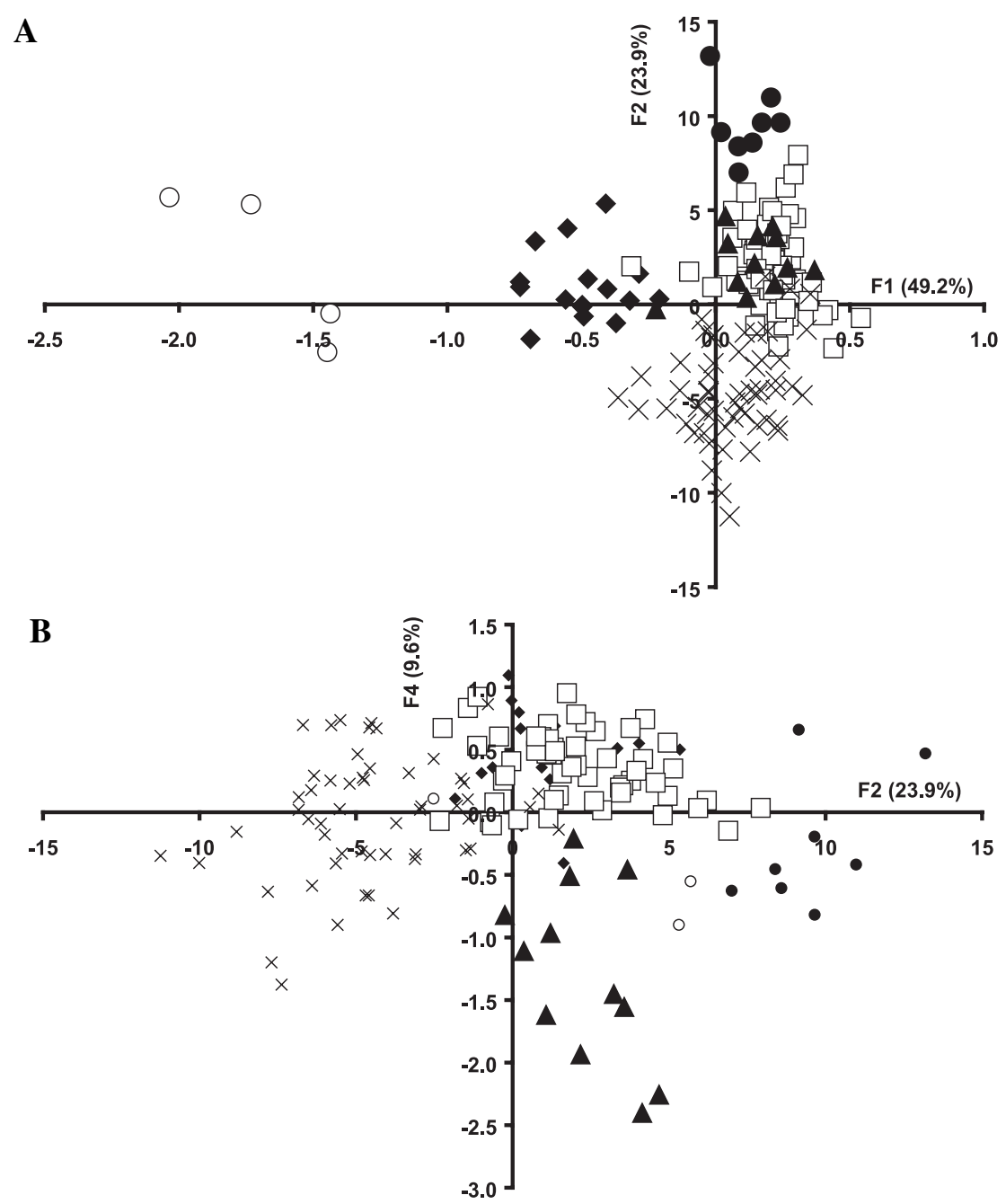

Figure 6. Discriminant analysis similarity maps determined: (A) by discriminant factors 1 and 2 for vitamin A spectra and (B) by discriminant factors 2 and 4. FDA performed on vitamin A spectra of the investigated cheeses: Austria $(\bullet)$, Switzerland $(\square)$, Germany $(\boldsymbol{\Delta})$, France $(\times)$, Finland $(\bullet)$ and Denmark $(\mathrm{O})$.

A correct classification was obtained for 93.9\% (data not shown) and $90.5 \%$ (Tab. I) of the calibration and validation spectra, respectively. It was concluded that vitamin A fluorescence spectra are fingerprints allowing a good identification of the geographic origin of Emmental cheeses. Table I gives the classification of the validation spectra into the six groups. As shown, 100\% of the cheeses from Germany, Finland and Denmark were correctly classified. Considering French cheeses, three samples were classified as belonging to the Switzerland group. For cheeses from Switzerland, three samples were misclassified: one cheese was with the Austria group, the second was with the Germany group and the last was with the France group. Finally, regarding cheeses 


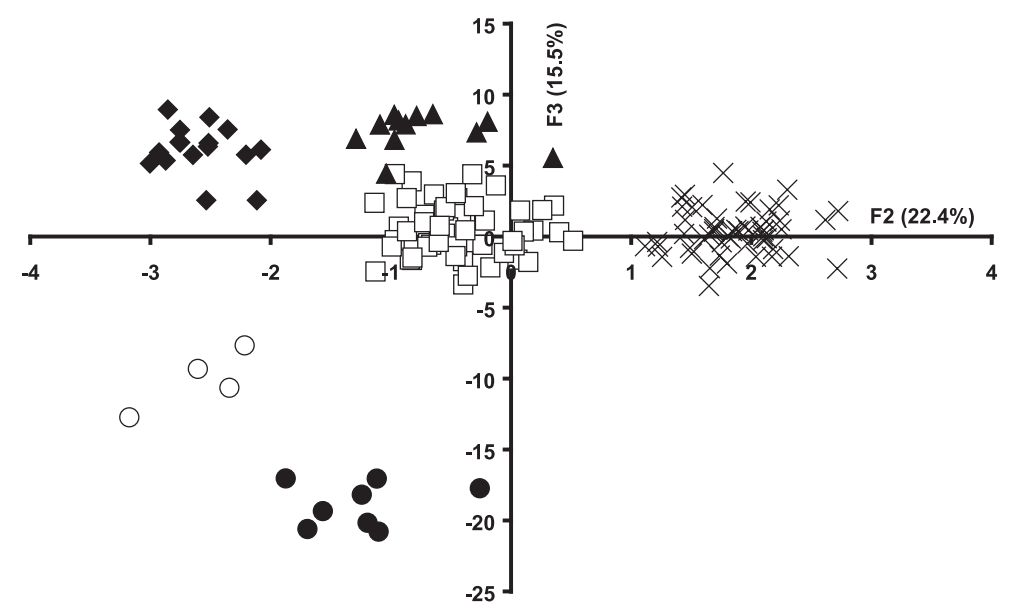

Figure 7. Discriminant analysis similarity maps determined by discriminant factors 2 and 3 . FDA performed on the first 20 concatenated PC of the PCA performed on the infrared and fluorescence spectral data of the investigated cheeses: Austria $(\diamond)$, Switzerland $(\square)$, Germany $(\boldsymbol{\Delta})$, France $(\times)$, Finland $(\mathbf{O})$ and Denmark $(\mathrm{O})$.

from Austria, only one cheese was misclassified. The results of the discriminant analysis are better with vitamin A fluorescence spectra than with tryptophan fluorescence spectra. They are in agreement with the results of others $[13,15]$ who have found that vitamin A is a useful probe for discriminating cheeses as a function of ripening [13] and/or the manufacturing processes [15]. Indeed, it was shown that a better classification of 8 different marketed soft cheeses was obtained from vitamin A spectra $(96 \%$ and $93 \%$ for principal and test samples, respectively) than from tryptophan spectra (95\% and $92 \%$, for principal and test samples, respectively) [13].

The current work confirms the high potential of a vitamin A probe as a useful tool for cheese authentication, and the results clearly indicate the possibility of applying this probe for recognising the geographic origin of Emmental cheeses.

\subsection{Global analysis of the infrared and fluorescence spectral data recorded on cheese: concatenation}

It is well known that (amide I and II) bands and tryptophan fluorescence spectra give specific information on the secondary and tertiary structures of proteins, respectively. Indeed, [18] have shown that a better discrimination of semi-hard cheeses as a function of the ripening time have been observed by the joint analysis of amide I and II spectra and tryptophan fluorescence spectra using common components and specific weight analysis (CCSWA). CCSWA allowed them to show that the two spectroscopic techniques are independent and information contained in each of their spectra refers to different phenomena.

In the current study, the concatenation method was applied to the 20 PCs of the PCA applied to each data set i.e., the 3000 $2800 \mathrm{~cm}^{-1}, 1700-1500 \mathrm{~cm}^{-1}$ and 1500 $900 \mathrm{~cm}^{-1}$ spectral regions, tryptophan and vitamin A fluorescence spectra. The map defined by the discriminant factors 2 and 3 of the FDA performed on the data is shown in Figure 7. It appears that such coupling is appropriate for the discrimination of Emmental cheeses. Considering that discriminant factor 2 accounted for $22.4 \%$ of the total variance, cheeses from France had positive score values, whereas the other cheeses had mostly negative score values. Cheeses from 
Table III. Classification table for the spectra of the validation group - Concatenated first 20 principal components of the PCA performed on MIR and fluorescence spectral data.

\begin{tabular}{lccccccc}
\hline Predicted $^{\text {a }}$ & Denmark & Finland & Austria & Germany & France & Switzerland & $\%$ well \\
Real & & & & & & & classified \\
\hline Denmark & $\mathbf{2}$ & - & - & - & - & - & 100 \\
Finland & - & $\mathbf{4}$ & - & - & - & - & 100 \\
Austria & 2 & - & $\mathbf{6}$ & - & - & - & 75 \\
Germany & - & - & - & $\mathbf{6}$ & - & - & 100 \\
France & - & 1 & - & 1 & $\mathbf{2 1}$ & 4 & 77.8 \\
Switzerland & - & - & 1 & 1 & 1 & $\mathbf{2 4}$ & 88.9 \\
\hline
\end{tabular}

${ }^{a}$ The number of cheeses predicted from the model. ${ }^{b}$ The number of real cheeses.

Austria and Germany had positive score values according to discriminant factor 3 , while cheeses from Denmark and Finland exhibited negative score values.

A correct classification was observed for $100 \%$ (data not shown) and $85.2 \%$ (Tab. III) of the calibration and validation samples, respectively. Table III gives the classification of the validation spectra for the six groups. This table shows that cheeses from Denmark, Finland and Germany were $100 \%$ discriminated. For Swiss cheeses, a correct classification was obtained for $88.9 \%$, since only 3 cheeses were misclassified. Regarding French cheeses, 6 cheeses were misclassified. The worst classification was obtained with cheeses from Austria since only $75 \%$ of correct classification was obtained.

It appears that the approach using concatenation of the five data sets allowed us to manage in a very efficient way all of the spectroscopic information collected on the 74 cheeses. As the spectroscopic techniques are independent, each of them provides information which can be used for recognising the geographic origin of Emmental cheeses. The concatenation method sums up all of this information on two discriminant factors (F2 and F3), taking into account the relation between the different data tables. These results, which were not obtained by FDA performed on tryptophan fluorescence spectra or infrared spectra alone, show that the methodology, consisting of the coupling of spectroscopies, is relevant for obtaining some information about cheeses. The proposed method is intended to fill a gap in the authentication of natural products and allow the discrimination of cheeses. It can be applied to the authentication of PDO cheeses.

\section{CONCLUSION}

Mid-infrared and fluorescence spectroscopies were investigated to find potential markers of geographic origin of Emmental cheeses produced during summer. Comparison of the results obtained from FDA indicated that better calibration as well as validation models may be obtained from fluorescence data (vitamin A) than from the mid-infrared data. These results show that fluorescence spectra recorded following emission at $410 \mathrm{~nm}$ directly on Emmental cheeses are fingerprints that allow the determination of the geographic origin of cheeses.

This study clearly indicates that the vitamin A fluorescence spectrum of such cheese is a fingerprint and that fluorescence spectroscopy coupled with chemometric techniques may be a reliable, rapid and cheap technique 
for the determination of the geographic origin of Emmental cheeses. The fluorescent properties of this molecule located in the core and the membrane of the fat globule are very sensitive to the physical state of the triglycerides and to the interactions between the fat globules and the protein matrix of the cheese. The current results are in agreement with previously published data indicating that fluorescence spectra are suitable for the identification of soft cheeses [13] and the determination of the geographic origin of Gruyère PDO cheeses [8]. In addition, the obtained results showed that the methodology, consisting of the coupling of spectroscopies using the concatenation technique, is relevant for the recognising of the geographical origin of Emmental cheeses.

\section{REFERENCES}

[1] Belton P., Spectroscopic methods for authentication: an overview, Biotechnol Agron. Soc. Environ. 4 (2000) 204-207.

[2] Bertrand D., Scotter C.N.G., Application of multivariate analyses to NIR spectra of gelatinized starch, Appl. Spectrosc. 46 (1992) 1420-1425.

[3] Christensen J., Povlsen V.T., Sørensen J., Application of fluorescence spectroscopy and chemometrics in the evaluation of processed cheese during storage, J. Dairy Sci. 86 (2003) 1101-1107.

[4] Collomb M., Spahni-Rey M., Steiger G., Dosage de la teneur en azote selon Kjeldahl de produits laitiers et de certaines de leurs fractions azotées à l'aide d'un système automatisé, Trav. Chim. Aliment. Hyg. 81 (1990) 499-509.

[5] Dufour E., Riaublanc A., Potentiality of spectroscopic methods for the characterisation of dairy products, I. Front-face fluorescence study of raw, heated and homogenised milks, Lait 77 (1997) 657-670.

[6] Dufour E., Lopez C., Riaublanc A., Mouhous Riou N., La spectroscopie de fluorescence frontale : une approche non invasive de la structure et des interactions entre les constituants des aliments, Agoral 10 (1998) 209215.

[7] Dufour E., Mazerolles G., Devaux M.F., Duboz G., Duployer M.H., Mouhous Riou N., Phase transition of triglycerides during semi-hard cheese ripening, Int. Dairy J. 10 (2000) 81-93.
[8] Dufour E., Karoui R., Bosset J.O., Utilisation de la fluorescence frontale intrinsèque de fromages de type L'Etivaz AOC et Gruyère AOC pour reconnaître leur origine géographique, Trav. Chim. Aliment. Hyg. 94 (2003) 379-393.

[9] Genot C., Tonetti F., Montenay-Garestier T., Marion D., Drapon R., Front-face fluorescence applied to structural studies of proteins and lipid-protein interactions of visco-elastic food products. 1. Designation of front-face adaptor and validity of frontface fluorescence measurements, Sci. Aliments 12 (1992) 199-212.

[10] Genot C., Tonetti F., Montenay-Garestier T., Marion D., Drapon R., Front-face fluorescence applied to structural studies of proteins and lipid-protein interactions of visco-elastic food products. 2. Application to wheat gluten, Sci. Aliments 12 (1992) 687-704.

[11] Herbert S., Caractérisation de la structure moléculaire et microscopique de fromages à pâte molle. Analyse multivariée des données structurales en relation avec la texture, Thèse, École Doctorale Chimie Biologie de l’Université de Nantes, France, 1999.

[12] Herbert S., Riaublanc A., Bouchet B., Gallant D.J., Dufour E., Fluorescence spectroscopy investigations of acid-and rennet-induced milk coagulation of milk, J. Dairy Sci. 82 (1999) 2056-2062.

[13] Herbert S., Mouhous Riou N., Devaux M.F., Riaublanc A., Bouchet B., Gallant J.D., Dufour E., Monitoring the identity and the structure of soft cheeses by fluorescence spectroscopy, Lait 80 (2000) 621-634.

[14] Jolliffe I.T., Principal Component Analysis, Springer, New York, USA, 1986.

[15] Karoui R., Dufour E., Dynamic testing rheology and fluorescence spectroscopy investigations of surface to centre differences in ripened soft cheeses, Int. Dairy J. 13 (2003) 973-985.

[16] Lakowicz J.R., Protein fluorescence, in: Lakowicz J.R. (Ed.), Principles of fluorescence spectroscopy, Plenum Press, New York, USA, 1983, pp. 63-93.

[17] Mazerolles G., Devaux M.F., Duboz G., Duployer M.H., Mouhous Riou N., Dufour E., Infrared and fluorescence spectroscopy for monitoring protein structure and interaction changes during cheese ripening, Lait 81 (2001) 509-527.

[18] Mazerolles G., Devaux M.F., Dufour E., Qannari E.M., Courcoux Ph., Chemometric methods for the coupling of spectroscopic techniques and for the extraction of the relevant information contained in the spectral 
data tables, Chem. Intel. Lab. Syst. 63 (2002) 57-68.

[19] Monin G., Recent methods for predicting quality of whole meat, Meat Sci. 49 (1998) S231-S243.

[20] Osborne B.G., Fearn T., Hindle P.H., Practical NIR spectroscopy with application in food and beverage analysis. 2nd edn., Longman Scientific \& Technical, New York, USA, 1993.

[21] Paradkar M.M., Sivakesava S., Irudayaraj J., Discrimination and classification of adulterants in maple syrup with the use of infrared spectroscopic techniques, J. Sci. Food Agric. 83 (2003) 714-721.

[22] Perez D.P., Sanchez M.T., Cano G., Garrido A., Authentication of green asparagus varieties by near-infrared reflectance spectroscopy, J. Food Sci. 66 (2001) 323-327.
[23] Piasentier E., Valusso R., Camin F., Versini G., Stable isotope ratio analysis for authentication of lamb meat, Meat Sci. 64 (2003) 239-247.

[24] Pillonel L., Badertscher R., Bütikofer U., Casey M., Dalla Torre M., Lavanchy P., Meyer J., Tabacchi R., Bosset J.O., Analytical methods for the determination of the geographic origin of Emmentaler cheese. Main framework of the project: chemical, biochemical, microbiological, colour and sensory analyses, Eur. Food Res. Technol. 215 (2002) 260-267.

[25] Robert P., Devaux M.F., Bertrand D., Beyond prediction: extracting relevant information from near infrared spectra, J. Near Infrared Spectrosc. 4 (1986) 75-84.

[26] Royer C.A., Approaches to teaching fluorescence spectroscopy, J. Biophys. 68 (1995) 1191-1195. 